African Journal for Physical, Health Education, Recreation and Dance (AJPHERD)

Vol. 15, No. 1 (March) 2009, pp. 62-73.

\section{BRINGING GOLF INTO SPORT PSYCHOLOGY SESSIONS THROUGH TECHNOLOGY (VIDEO-FOOTAGE)}

\section{Lourens Human, Drikus Kriek and Theo Bezuidenhout}

\section{ABSTRACT}

Technology has entered many spheres of modern day society. The sport context has also been infiltrated by technology, as can be seen in how video-footage is used in coaching, biomechanics, as well as umpiring/refereeing. This research focused on using video-footage during sport psychology sessions in golf. Stage 1 entailed the videotaping of six golfers from the Tshwane University of Technology's Golf Academy (TUTGA) during a practice session. During Stage 2 the six golfers viewed the video-footage that was made of the practice session, and indicated what they deemed relevant to be discussed during one-to-one sport psychology sessions. Stage 3 entailed one-to-one sport psychology sessions informed by narrative practice with the six golfers respectively, during which the identified material from Stage 2 was discussed. During Stage 4 a focus group session was held with the six golfers during which they were asked to narrate their experiences of being videotaped during a practice session, as well as discuss this video-footage during one-to-one sport psychology sessions. These focus group discussions were videotaped, transcribed and analyzed through a process of narrative analysis. It seems that using video-footage allowed the golfers to voice their specific sport psychology needs, which allowed for their specific needs to be addressed collaboratively (between a sport psychologist and golfer) in a contextual manner. Therefore, from this study it seems that using video-footage during sport psychology sessions with golfers, added value to the sport psychology process.

Key words: Golf, technology, videotaping, video-footage, narrative practice, narrative analysis.
Lourens Human, PhD Psychology

Theo Bezuiden hout

Department of Psychology,

University of Pretoria, Pretoria,

South Africa

E-mail:lourens.human@.up.ac.za

Drikus Kriek, PhD Psychology

Centre for Business Leadership,

University of South Africa

South Africa.

\section{INTRODUCTION}

Technology has found its way into nearly every area of modern society as indicated by, for example, the role it plays in the corporate world, the economic sphere, the health care system, the agricultural environment and the education sector. Technology has also profoundly influenced modern day sport (Loland, 2003), as found in coaching (Woodward, 2005), biomechanics (Eslami, Begon, Faraphour \& Allard, 2007) and umpiring/refereeing (Nevill, Balmer \& Williams, 2002). The same trend is seen in the use of technology in the field of sport psychology where audio, as well as audio-visual technology, has entered the field (Miller, Ogilvie \& Adams, 2000). According to the "MultiClassification System for Sport Psychology" (MCS-SP) by Gardner and Moore $(2004 ; 2006)$ the role and work of a 
sport psychologist ${ }^{1}$ in the sport context can be described in terms of a four level classification system, being "Performance Termination" (L1), "Performance Impairment" (L2) and "Performance Dysfunction" (L3). All three these levels require sports counselling interventions. The last level is "Performance Development" (L4) and requires sport psychology interventions, which can be done through an applied sport psychology approach (delivered through a Psychological Skills Training (PST) programme) or a clinical sport psychology approach (delivered through a Mindfulness-AcceptanceCommitment (MAC) programme).

This article is concerned with the use of video-footage, as a form of technology, within sport psychology. Therefore, the goal of this article is to describe how videofootage can be used to assist sport psychology sessions for "Performance Development" (L4) (MCS-SP) in golf.

\section{LITERATURE}

The review of literature is confined to the use of video-footage in coaching, biomechanics and umpiring/refereeing and aims to provide the background of how it can be used in sport psychology.

\section{Coaching}

Coaching is one of the areas in the sport context where video-footage has been used in both technical and tactical analysis.

\section{Technical Analysis}

Technical analysis refers broadly to the process of using video-footage to study athletes performing sport specific skills, coaches giving feedback to athletes on the quality of the performance of the sport specific skills, with the purpose of giving corrective feedback to athletes thereby ensuring that faults pertaining to the performance of sport specific skills can be rectified more effectively (Straub, 2006).

\section{Tactical Analysis}

Video-footage is not just used in the field of technical analysis, but it is also used in the sphere of tactical analysis. Tactical analysis entails the process of using video-footage for studying one's own tactics in sport, as well as the tactics employed by opponents. Coaches and athletes can employ videofootage for tactical analysis (Griffiths, 1997; Woodward, 2005).

\section{Biomechanics}

Biomechanics is an interdisciplinary science, which focuses on the mechanics of 
the human body (Luttgens \& Hamilton, 1997). Biomechanical analysis has become widely used in modern day sport, as it allows coaches and athletes the opportunity to take analysis of the sporting technique a step further. Where technical analysis by coaches and athletes is often done with the naked eye, using normal video-footage, biomechanical analysis is more technologically advanced. High-speed cameras can be used to show super slow-motion video-footage of athletes performing sport specific skills (Eslami et al., 2007). Biomechanical analysis allows for corrective feedback on the execution of sport specific skills, thereby also contributing to injury prevention (Peterson \& Renstrom, 1995).

\section{Umpiring/Refereeing}

Umpiring/Refereeing is another area in the sport context where video-footage has been used in both technical and tactical analysis.

\section{Evaluating Umpires/Referees}

Video-footage is not only being used to analyse the performances of athletes, it is also being used to scrutinise umpires/referees, specifically their performances during matches and how they interpreted rules in the heat of competition (Nevill et al., 2002).

\section{Assisting Umpires/Referees}

In the last decade video-footage has also been used in assisting umpires and match officials. These improvements include better scoring methods and techniques, improved education of umpires and officials involved in sporting contests as well as assisting umpires with on-field decisions (Griffiths, 1998; Nevill et al., 2002).

\section{Sport Psychology}

Sport psychology has also started to include various forms of technology in its services and this has led to the improvement of services presented by sport psychologists all over the world (Miller et al., 2000; Singer, 1992). Sport psychologists often use audio technology to play music during training sessions in relaxation techniques with athletes (Bull, 1991; Cox, 1994; Potgieter, 1997). Furthermore, audio-visual (e.g. Microsoft PowerPoint) equipment has improved over the last 20 years and it has become a medium of improving the delivery of sport psychological services. 
A specific way of doing this is making sport psychology presentations better and more attractive to all users of sport psychological services (Anderson, Miles, Robinson \& Mahoney, 2004).

In conclusion, it seems that on the one hand technology in general has claimed an important place in the sport context, while on the other hand video-footage as a form of technology has profoundly influenced coaching, biomechanics and umpiring/refereeing. Furthermore, it seems that limited information is available to show how video-footage has been used in the field of sport psychology and it seems that it has not been employed to the same degree as in coaching, biomechanics and umpiring/refereeing. This article attempts to fill this gap by describing how video-footage was used during sport psychology sessions for "Performance Development" (L4)(MCS-SP) in golf and indicating how the use of video-footage could shape sport psychology sessions.

\section{METHOD}

\section{Context}

This research took place within the general context of the Tshwane
University of Technology (TUT), in Pretoria, South Africa and specifically within the context of this institution's golf academy. The Tshwane University of Technology's Golf Academy (TUTGA) resides with the Department of Sport, Rehabilitation and Dental Sciences in the Faculty of Sciences and its purpose is to develop, present and manage golf-related programmes in collaboration with TUT (TUT, 2008a, 2008b).

\section{Participants}

The participants in this research were six students from TUT, who were also golfers in TUTGA. One of the researchers was employed as "mental coach" at TUTGA at the time the research was conducted, and therefore the golfers were available to participate in the research. The participants were all white males, between 19 and 24 years of age, and were invited to participate in this research as they had the highest scores on the internal ranking system at TUTGA. This could be seen as a form of convenience sampling (Guy, Edgley, Arafat \& Allen, 1987). 
A limitation of this study is that the six golfers were not representative of golfers in the South African society.

\section{Material}

The material used in this research was produced through a process that entailed the following stages:

\section{Stage 1: Taping Golf}

One of the researchers videotaped the six golfers while playing golf for nine holes on a golf course. The videofootage specifically focussed on shots around the greens, as well as on the golfers' putting.

\section{Stage 2: Viewing Golf}

The golfers viewed the video-footage individually with one of the researchers. Each golfer was afforded the opportunity to view his performance and to indicate to the researcher what he found relevant in the video-footage to discuss during sport psychology sessions.

\section{Stage 3: Personal Session}

One of the researchers conducted a oneto-one sport psychology session with each of the six golfers, in which the material identified by the golfers in Stage 2 was discussed in depth. The duration of these individual sport psychology sessions was one hour each; they were unstructured in nature (Fontana \& Fry, 2000; Miller \& Brewer, 2003) and primarily informed by narrative practice. Narrative can be seen as the primary metaphor available to people to make sense of experiences (Edwards, 1997; Human, 2008a, 2008b; Monk, Winslade, Crocket \& Epston, 1997). Although these sessions were videotaped, they were not used for analytical purposes, but formed the context for the focus group sessions of Stage 4.

\section{Stage 4: Focus Group Session}

All the golfers then participated in a sport psychology focus group session held with the six golfers (Bryman, 2004). The goal of the focus group was to allow the six golfers to narrate their experiences of being videotaped on the golf course and use the video-footage during sport psychology sessions. The focus group session was also videotaped, the focus group discourse transcribed by the researchers (Clandinin \& Connelly, 2000; Riessman, 1993) and the narratives of the six golfers analyzed by means of narrative analysis. 
This material was used in this research.

Although there are various methods for analyzing narrative (e.g. paradigmatic analysis, structural analysis) (Riessman, 1993; Sparkes, 1999), narrative analysis is an inductive reading of the text with the purpose of understanding how people make sense of their experiences (Gergen, 1998; Human \& Thomas, 2008; Human, 2008; Riessman, 1993). In this article narrative analysis was used to try and understand how the six golfers who participated in this research made sense of using video-footage during individual sport psychology sessions.

\section{Ethics}

Permission to conduct the research was granted to the researcher by TUTGA. All six golfers were informed about the nature of the research and participated voluntarily in this study. Ethical clearance for the research was granted by the "Research and Ethics Committee" in the Faculty of Humanities at the University of Pretoria (UP).

\section{RESULTS}

For practical reasons the entire narratives of the six golfers are not portrayed in this article. Only the values of using video-footage, as well as a practical example from the narratives of the six golfers are portrayed. Suggestions are also made on how the specific needs as portrayed in the practical examples of the six golfers could be explored between a sport psychologist and the six golfers during sport psychology sessions.

\section{Golfer 1: Learn through Video- footage}

Value

Golfer 1 is of the opinion that using video-footage during sport psychology sessions for golf afforded him the opportunity to learn about himself. $\mathrm{He}$ states, "you have a general picture of yourself on the golf course, but to see yourself on camera is something totally different and you can learn a lot about yourself in this manner".

\section{Example:}

Golfer 1 gives the following example of the value of using video-footage to learn about himself during sport psychology sessions for golf:

"On the video I saw that I was in a hurry with my pre-shot routine ... the practice session that was not very serious. In a tournament I shall take my time and be more serious about my preshot routine. I also noticed that I am in a hurry 
when it comes to putting. Being captured on video helps one see these aspects of one's golf."

\section{Session}

During sport psychology sessions a sport psychologist and Golfer 1 could address the specific aspect of being in a hurry in a collaborative manner. This would entail exploring the relationship between a golf practice session (context) - being in a hurry (phenomenon) - performance development (L4)(MCS-SP). This exploration could also be translated to the context of tournaments and would allow Golfer 1 to learn more about himself.

\section{Golfer 2: Evaluate through Video-footage}

Value

Golfer 2 is of the opinion that using videofootage during sport psychology sessions for golf afforded him the opportunity to evaluate himself. He states,

"seeing yourself on camera, I think, helps a helluva lot. A real step-up could you say in technology ... So seeing yourself do it and how you can improve it, helps a tremendous load".

Example

Golfer 2 gives the following example of the value of using video-footage to evaluate himself during sport psychology sessions for golf:

"I think visualisation plays a big role. I mean visualising the shot, seeing what you have to actually achieve and what you must do helps a lot and your confidence, in the way you play and as a player. You pick it up on the camera which is nice after the thing, to see how long did you take, did you actually have a look at what you were going to do before your shot."

Session

Golfer 2 expressed that the value of using video-footage lies in being able to evaluate himself in, for example the application of a psychological skill, like visualization. A sport psychologist and Golfer 2 could work together during sport psychology sessions and discuss the interaction between a golf practice session (context) - visualization (phenomenon) - performance development (L4)(MCS-SP). The application of psychological skills, like visualization during tournaments, could also be addressed during sport psychology sessions.

\section{Golfer 3: Improve through Video-footage}

Value

Golfer 3 is of the opinion that using videofootage during sport psychology sessions for golf afforded him the opportunity to improve himself. He states:

\footnotetext{
"physically all the pro's are on the same level ... it is here (points to his head) that the 'good' guys are separated from the 'alright' guys. It can only improve one's game".
}

Example:

Golfer 3 gives the following example of the value of using video-footage to improve his skills during sport psychology sessions for golf: 
"I saw that my pre-shot routine is not consistent ... It was especially with my pressure putts that I did not do my pre-shot routine properly and which made me miss those putts ... Being video-taped also helps one deal with the pressure of being on camera, as one is always going to be on camera and watched by crowds once we turn pro ... video-taping us while practicing is like creating a small US Open."

Session

During sport psychology sessions a sport psychologist and Golfer 3 could address the specific aspects of inconsistency, as well as dealing with pressure caused by cameras and crowds.

The relationship between a golf practice session (context) - inconsistency (phenomenon) - performance development (L4)(MCS-SP) could be addressed in a collaborative manner, as well as the interaction between cameras and crowds (context) - pressure (phenomenon) - performance development (L4)(MCS-SP). Dealing with these specific needs could assist Golfer 3 in improving himself, not just in practice sessions but also during tournaments.

\section{Golfer 4: Confidence through Video- footage}

Value

Golfer 4 is of the opinion that using video-footage during sport psychology sessions for golf created an opportunity for building confidence. He states: "when you lose confidence you need to see what mistakes you are making and try not to make them again. You also need to look at the things that you are doing right on the camera."

Example

Golfer 4 gives the following example of the value of using video-footage to build confidence during sport psychology sessions for golf:

\footnotetext{
"I a m sure Tiger Woods also watches videos of him playing in major tournaments. One needs to identify the mistakes you made, but also focus on those aspects of your golf that are right. In this way you can build confidence again."
}

\section{Session}

Discussing the relationship between a golf practice session (context) negative and positive aspects of Golfer 4's golf (phenomenon) - performance development (L4) (MCS-SP) during sport psychology sessions with a sport psychologist, could help Golfer 4 in building confidence in his game of golf. However, it is important that attention is also paid to the aspect of confidence during tournaments.

\section{Golfer 5: Focus through Video- footage}

Value

Golfer 5 is of the opinion that using video-footage during sport psychology 
sessions for golf created an opportunity

to stay focussed. He states:

"you are busy with your game and you should not pay attention to what is being videotaped. You will have an opportunity later to watch the video. On the golf course you need to focus on playing the game."

Example:

Golfer 5 gives the following example of the value of using video-footage during sport psychology sessions for golf:

"I think it is important that the camera is also used for psychology, as it is always used for technical stuff like how your swing must be in sync. One can now look at your body posture, pre-shot routine and how you behave on the golf course. The camera allows one to view your behaviour, to see which of your behaviour has nothing to do with golf."

Session

During sport psychology sessions a sport psychologist and Golfer 5 could address the specific aspect of "pro-golf" and "anti-golf" behaviour. This would entail exploring the relationship between a golf practice session (context) - "pro-golf" and "anti-golf" behaviour (phenomenon) - performance development (L4)(MCS-SP). This exploration could also be translated to the context of tournaments and would allow Golfer 5 to stay focussed when participating in golf.

\section{Golfer 6: Perspective through Video- footage}

Value
Golfer 6 is of the opinion that using video-footage during sport psychology sessions for golf created an opportunity to form a different perspective of himself. He states:

"you have this impression of yourself, you know, but when you see yourself on camera it changes the perspective of yourself'.

Example:

Golfer 6 gives the following example of the value of using video-footage during sport psychology sessions for golf:

"When you get into a situation where you, you don't actually quite know what's, what's happening, like you have a tricky putt whatever, you often said to me if I made a mistake you could see it coming because my body language portrayed that I was unsure and am a lot of the times."

Session

A sport psychologist and Golfer 6 could during sport psychology sessions work together and address the whole aspect of Golfer 6 being unsure of himself. This could be done by taking cognisance of a golf practice session (context) - being unsure of oneself (phenomenon) performance development (L4) (MCSSP). Through this mutual exploration Golfer 6 could arrive at a different perspective of himself. It could also be helpful to contextualize being unsure of oneself in tournaments. 


\section{DISCUSSION}

The results indicate that the use of video-footage as part of the sport psychology sessions, created an opportunity to address the specific needs of the six golfers; allowed for viewing particular phenomenon in a contextual manner, and established the possibility for collaboration to take place between one of the researchers and the six golfers, respectively.

Firstly, traditional sport psychology is about presenting generic psychological skills (e.g. goal-setting, imagery, arousal control, communication, motivation) that do not always account for an athlete's specific sport psychology needs (Gill, 2001; Murphy, 1995). The danger, therefore, exists that a sport psychologist can see these generic psychological skills as applicable to all athletes in all sports. By employing video-footage technology these potential limitations are overcome and specific needs of individual athletes can be addressed.

Secondly, traditional sport psychology functions from a cognitive-behaviour perspective, which is based on a positivist epistemology and individualistic in nature. Therefore, an athlete's behaviour is determined by his/her inner word (cognitions and emotions)(Gardner, 2001; Singer, 1992). The danger, therefore, exists that the contextual influences (e.g. social sphere, sport environment) are often ignored. By using video-footage as described in this article a sport psychologist and athletes can contextualize the specific phenomena that are addressed during sport psychology sessions.

Lastly, traditional sport psychology often makes use of didactic instruction in the delivery of psychological skills to athletes.

The application of video-footage in this study allows for collaboration between sport psychologist and an athlete and therefore is a more co-constructing process.

\section{CONCLUSION}

Although the use of video-footage during sport psychology sessions can at times be labour intensive and expensive when used during individual sport psychology sessions, it can be concluded from this study that the use 
of video-footage in sport psychology

can assist sport psychologists to

enhance the psychological processes to

be specific, contextual and

collaborative. It is suggested that video-

footage primarily be used for

"Performance Development"

(L4)(MCS-SP) with semi-professional

and professional athletes.

\section{REFERENCES}

Anderson, A., Miles, A., Robinson, P. \& Mahoney, C. (2004). Evaluating the athlete's perception of the sport psychologist's effectiveness: What should we be assessing? Psychology of Sport and Exercise, 5, 255-277.

Bryman, A. (2004). Social Research Methods $\left(2^{\text {nd }}\right.$ ed.). Oxford: Oxford University Press.

Bull, S.J. (1991). Sport Psychology: A Self-help Guide. Ramsbury: Crowood Press.

Clandinin, D.J. \& Connelly, F.M. (2000). Narrative Inquiry. Experience and Story in Qualitative Research. San Francisco: Jossey Bass.

Cox, R.H. (1994). Sport Psychology: Concepts and Applications ( $3^{\text {rd }}$ ed.). Dubuque: WCB Brown \& Benchmark.

Edwards, D. (1997). Discourse and Cognition. London: Sage.

Eslami, M., Begon, M., Faraphour, N. \& Allard, P. (2007). Forefoot-rearfoot coupling patterns and tibial internal rotation during stance phase of barefoot versus shod running. Clinical Biomechanics, 22, 74-80.

Fontana, A. \& Frey, J.H. (2000). From structured questions to negotiated text. In N.K. Denzin \& Y.S. Lincoln (Eds.), Handbook of Qualitative Research (pp. 645-668). Thousand Oaks: Sage.

Gardner, F.L. (2001). Applied sport psychology in professional sports: the team psychologist.
Professional Psychology: Research and Practice, 32, 34-39.

Gardner, F.L. \& Moore, Z.E. (2004). The multilevel classification system for sport psychology (MCS-SP). The Sport Psychologist, 18, 89-109.

Gardner, F.L. \& Moore, Z.E. (2006). Clinical Sport Psychology. Champaign: Human Kinetics.

Gergen, K.J. (1998). Narrative, moral identity and historical consciousness: A social constructionist account. Retrieved on March 30, 2006 from http://www.swarthmore. edu.

Gill, D.L. (2001). Feminist sport psychology: A guide for our journey. The Sport Psychologist, $15,363-372$.

Griffiths, E. (1997). Kitch: Triumph of a Decent Man. Cape Town: CAB.

Griffiths, E. (1998). Jonty: Fruits of the Spirit. Cape Town: CAB.

Guy, R.F., Edgley, C.E., Arafat, I. \& Allen, D.E. (1987). Social Research Methods. Puzzles and Solutions. London: Allyn \& Bacon.

Hays, K.F. (1995). Putting sport psychology into (your) practice. Professional Psychology: Research and Practice, 26, 33-40.

Human, L.H. \& Thomas, M. (2008). Playing sport in the stormy sea of street life. African Journal for Physical, Health Education, Recreation and Dance, 14, 206-220.

Human, L.H. (2008). Unique outcomes in professional psychology training through an adventure programme. Acta Academia, 40, 151174.

Loland, S. (2003). Technology in sport: three ideal-typical views and their implications. Professional Psychology: Research and Practice, 32, 34-39.

Luttgens, K. \& Hamilton, N. (1997). Kinesiology: Scientific Basis of Human Motion. Dubuque: Brown \& Benchmark.

Miller, R.L. \& Brewer, J.D. (2003). The A-Z of Social Research: A Dictionary of Key Social Science Research Concepts. London: Sage. 
Miller, T.W., Ogilvie, B. \& Adams, J. (2000). Sport Psychology: issues for the Consultant. Consulting Psychology Journal: Practice and Research, 52, 269-276.

Monk, G., Winslade, J., Crocket, K., \& Epston, D. (1997). Narrative Therapy in Practice: The Archaeology of Hope. San Francisco: JosseyBass.

Murphy, S.M. (1995). Introduction to sport psychology interventions. In S.M. Murphy (Ed.), Sport Psychology Interventions (pp. 115). Champaign: Human Kinetics.

Nevill, A.M., Balmer, N.J. \& Williams, A.M. (2002). The influence of crowd noise and experience upon refereeing decisions in football. Psychology of Sport and Exercise, 3, 261-272.

Peterson, L. \& Renstrom, P. (1995). Sports Injuries. Their Prevention and Treatment. London: Martin Dunitz Ltd.

Potgieter, J.R. (1997). Sportsielkunde: Teorie en praktyk. Pretoria: Van Schaik.

Riessamn, C.K. (1993). Narrative Analysis. Newbury Park: Sage.

Singer, R.N. (1992). What in the world is happening in sport psychology. Journal of Applied Sport Psychology, 4, 63-76.

Singer, R.N. (1992). Coleman Griffith memorial lecture. Journal of Applied Sport Psychology, 4, 63-76.

Sparkes, A.C. (1999). Exploring body narratives. Sport, Education and Society, 4, 1730.

Straub, W.F. (2006). Digital Sport Psychology. Retrieved on April 7, 2006, from http://www.thesportj ournal.org.

Suedfeld, D. \& Bruno, T. (1990). Flotation rest and imagery in the improvement of athletic performance. Journal of Sport and Exercise Psychology, 12, 82-85.

Tshwane University of Technology (TUT). (2008a). Department of Sport, Rehabilitation and Dental Sciences. Students. Retrieved September 24, 2008 from http://www.tut.ac.za.
Tshwane University of Technology (TUT). (2008b). Department of Sport, Rehabilitation and Dental Sciences. Brochure. Retrieved September 24, 2008 from http://www.tut.ac.za.

Woodward, C.R. (2005). Winning! London: Hodder and Stoughton. 